A TEXTBOOK ON THE NURSING AND DISEASES OF SICK GHILDREN FOR NURSES

Edited by Alan MoncriefF, M.D., F.R.C.P. 4th Edition. Price 30 s.

This is one of the most valuable and readable books on the nursing and diseases of sick children.

Each step of diagnosis and treatment is carefully explained, and together with the excellent diagrams, serves to clarify the subject matter.

This edition has been thoroughly revised, is well arranged and up-to-date, and includes many new details of nursing procedures. It is essentially an outstanding textbook for the classroom.

Although there have been many changes in authorship, the editor has again had the co-operation of various specialists, each of whom is a recognized authority on his subject.

\section{FOOD AND NUTRITION}

The Physiological Bases of Human Nutrition

By E. W. R. Cruickshank, M.D., D.Sc., Ph.D.' M.R.C.P. E. \& S. Livingstone. Edinburgh. 1946. Price r6s.

Considering the enormous scope of the subject and the relatively small size of the book, Professor Cruickshank has done a very good service in presenting the salient facts relating to food and nutrition. It is essentially brief and compressed, which makes reading difficult but for those who wish to study this subject there is much food for thought and much nutrition in the extensive bibliography. The final chapter which deals with the Food and Agricultural world organization is particularly good. There are chapters dealing with the history of nutritional development, bread, milk, dehydrated and later, dietetics,' standards, etc., all of which are stimulating to those interested. There is a multiplicity of graphs and tables but a complete absence of chemical formulae-an interesting innovation.

\section{A PRACTICAL HANDBOOK OF MIDWIFERY AND GYNAEGOLOGY}

By W. F. T. Haultain and Clifford Kennedy. 3rd Edition. E. \& S. Livingstone. Edinburgh. Pp. 380. Price 20s.

Into the space of 380 pages the authors have managed to encompass the whole of the modern practical teaching relating to midwifery and gynaecology. It is a book which must have a wide appeal to students, and general practitioners will be well repaid by reading it. The moderate price is a helpful feature but it is to be hoped that in future editions, which we are sure will follow, more illustrations especially relating to the midwifery section will be added. Maybe also the authors will choose to co-relate breast and artificial feeding in the general layout. The section on the infant is especially good but the subject of the $R h$ factor needs some enlargement. The Edinburgh school has always enjoined a rich reputation in the subject of midwifery and these two teachers have not only upheld that tradition but we feel enhanced it by writing this book.

\section{TEXTBOOK OF MEDICAL TREATMENT}

By various authors. Edited by D. M. Dunlop, L. S. P. Davidson and J. W. MCNeE. 4th Edition. E. \& S. Livingstone. Edinburgh. 1946. . Price 3os.

The popularity of the earlier editions of this valuable tome on medical therapeutics is bound to be not only upheld but considerably increased by the change in format and the careful revision which has taken place in this, the fourth edition. The third edition had got out of hand with its size and the change over to a larger page has produced an ideal book. The titling and sub-titling is also excellent in this production.

As always, the editors have remained true to their original promise of discussing general and specific treatment rather than of giving catalogues of multifarious drugs which have been or can be used in the empirical treatment of some disease process. Their approach to the recent advances in the field of therapeutics, especially the antibiotics and such drugs as thiouracil, is masterly. They have not, in their enthusiasm, cast away the old for the new.

There can be no doubt at all that all doctors who have to treat patients should assiduously study this book for with it they will be able to bring the benefit of modern therapeutics to every one and by so doing increase their own medical reputation. The unfortunate occurrence of the total loss of the printers" type of the third edition has been turned to great advantage by the hard work and painstaking care of the authors and editors.

\section{TEXTBOOK OF OBSTETRICS}

By G. I. Strachan, M.D. (Glas.), F.R.C.P., F.R.C.S., F.R.C.O.G. H. K. Lewis. Pp. xi and $732.45 \mathrm{~s}$.

The customary remark that there is no place for yet another textbook of midwifery is quite unfounded, for there is a survival of the fittest among textbooks ; students select those that they find most helpful, and competition raises the general standard. This is a praiseworthy book, obviously based on the author's long experience, and it can safely be recommended as a complete and orthodox account of obstetric practice. It is attractively printed; and the wide royal octavo pages are well related to the thickness of the book, so that it lies comfortably open on the desk; points of importance to the labouring student. The numerous photographs are excellent but the same cannot be said of the rather sketchy figures. For example in Fig. 3 the uterine tubes are like enormous corridors, in Fig. 273 the crude forceps pass through the perineum, and Fig. 